\title{
SELECTIVE CRYSTALLIZATION OF SILICOALUMOPHOSPHATE SAPO-11 WITH A MICROMESOPOROUS STRUCTURE
}

\author{
Zulfiya Khayrullina $^{\text {a }}$, Kanaan Ramadan Ahmed ${ }^{\text {b,*, Samara Kambarova }}{ }^{\mathrm{C}}$, Marat Agliullin ${ }^{\mathrm{d}}$ \\ ${ }^{a}$ Ufa State Petroleum Technological University, Ufa, Russia- (zul93@yandex.ru) \\ ${ }^{\mathrm{b}}$ Dept. of Chemistery, Faculty of Science, University of Zakho, Kurdistan Region, Iraq- (kanaan.ahmed@uoz.edu.krd) \\ ${ }^{\mathrm{c}}$ Bashkir State University, Ufa, Russia- (maratradikovich2@mail.ru) \\ d laboratory preparation of catalysts, Institute of Petrochemistry and Catalysis of Russian Academy of Sciences \\ Ufa, Russia- (maratradikovich@mail.ru)
}

\begin{abstract}
:
The authors have proposed a method for the selective crystallization of a SAPO-11 silicoaluminophosphate molecular sieve with a micro-mesoporous structure. It has been shown that crystallization of a silicoaluminophosphate gel, in the preparation of which its isopropoxide is used as a source of aluminum, makes it possible to obtain a SAPO-11 molecular sieve with a specific surface area of $\sim 207 \mathrm{~m}^{2} / \mathrm{g}$, a volume of micro- and mesopores of $\sim 0.08$ and $0.09 \mathrm{~cm}^{3} / \mathrm{g}$. , respectively. Using scanning electron microscopy, it was demonstrated that the crystals of the material are pseudospherical particles $\sim 8-10$ microns in size, consisting of aggregates of nanocrystals $\sim 100-200 \mathrm{~nm}$ in size.
\end{abstract}

KEYWORDS: Mesoporous Zeolites, Heterogeneous Catalysis, Zeolites, SAPO-N Silicoaluminophosphates, Hydroisomerization of Higher Paraffins

\section{INTRODUCTION}

The most developed countries of the world are constantly improving old technologies and creating new technological processes in order to obtain high-quality, environmentally friendly motor fuels and other marketable oil products. At present, one of the new resource-saving processes in the field of oil refining is catalytic hydroisomerization based on selective hydroisomerization of $\mathrm{C}_{16}+$ and higher n-paraffins. This process makes it possible to obtain high-quality, low-solidifying diesel fuels and synthetic base oils of III and III + groups in high yields, as well as due to the selective conversion of n-paraffins into isoparaffins [1-4].

From the data analysis of literature, it follows that promising catalysts for the process of hydroisomerization of n-paraffins $\mathrm{C}_{7}-\mathrm{C}_{16}$ can be used as a catalyst based on medium-pore zeolite materials with a one-dimensional channel porous structure, such as ZSM-22, ZSM-23, SAPO-11, SAPO-31, and SAPO-41 [5, $6]$. Among these molecular sieves, silicoaluminophosphate SAPO-11 is of particular interest due to the presence of elliptical pores with a size of $4.0 \times 6.5 \AA$ and acid sites of "moderate" strength [7]. Thus, on the basis of this material, Chevron has developed a process for producing low-solidifying diesel fuels and synthetic base oils of the III-group [8]. The authors of works $[9,10]$ showed the high activity and selectivity of SAPO-11 in the hydroisomerization of n-heptane and n-octane, respectively. At the same time, the problem of the formation of a micromesoporous structure, which would increase the stability of catalysts based on the SAPO-11 molecular sieve in the process of hydroisomerization of higher n-paraffins, remains urgent. Various methods are known for the formation of a mesoporous structure in zeolitic materials: removal of atoms from the framework structure (dealumination, desilication, irradiation), the use of co-templating with surfactant materials, the use of solid templates (carbon materials, polymers, etc.), zeolitization of processed solids, silylation, and a combination of these methods [11-14]. In $[15,16]$, in order to create secondary mesopores, it is proposed to introduce pore-forming templates based on the various surfactants. In $[17,18]$, to create secondary meso- and macropores, it initiates the treatment with SAPO-11 for partial destruction of the crystal lattice. The main disadvantage of the above methods is the low degree of crystallinity of the obtained materials, the high cost and low availability of pore-forming templates. Therefore, it is necessary to develop a method for creating secondary meso- and macro-pores in SAPO-11 without using of templates and postsynthetic treatments. This work is devoted to its solution.

\section{EXPERIMENTAL}

\subsection{Synthesis of micro-mesoporous silicoaluminophosphate}

Samples SAPO-11 were prepared by hydrothermal synthesis from a reaction gel of the following composition: $1.0 \mathrm{Al}_{2} \mathrm{O}_{3}$. $1.0 \mathrm{P}_{2} \mathrm{O}_{5} \cdot 0.4 \mathrm{SiO}_{2} \cdot 1.0 \mathrm{DPA} \cdot 30 \mathrm{H}_{2} \mathrm{O}$. Phosphoric acid $(85 \%$, $\mathrm{H}_{3} \mathrm{PO}_{4}$, Reakhim), Aluminum isopropoxide (98\%, IA, Acros Organics), tetraethylorthosilicate (TEOS), and di-npropylamine (99\%, DPA, Acros Organics), respectively.

The silicoaluminophosphate gel was synthesized as follows: $19.4 \mathrm{~g}$ of distilled water was added to $10.0 \mathrm{~g}$ of orthophosphoric acid, $17.3 \mathrm{~g}$ of Aluminum isopropoxide was added gradually to the resulting solution and mixed vigorously for 1 hour, then 4.4 $\mathrm{g}$ of dihydrogen was added to the resulting gel. n-propylamine and $3.5 \mathrm{~g}$ TEOS and kept at room temperature for 24 hours. The prepared gel is designated Gel-SAPO. Subsequently, the resulting gel was crystallized at $180^{\circ} \mathrm{C}$ for 10 hours in stainless steel autoclaves with a special fluoroplastic coating. The crystalline SAPO-11 sample is designated Meso-SAPO-11. 


\subsection{Investigation of Physico-chemical Properties of the obtained materials}

The chemical composition of the obtained silicoaluminophosphates was analyzed by X-ray fluorescence spectrometry on an EDX 720 / 900HS instrument (Shimadzu). $\mathrm{X}$-ray phase analysis (XRD) of dried SAPO gels and uncalcined SAPO-11 samples was performed on a Bruker D8 Advance diffractometer in $\mathrm{CuK} \alpha$ radiation. Scanning was carried out in the range of $2 \theta$ angles from 3 to $50-80^{\circ}$ with a step of $1 \mathrm{deg} /$ min, the accumulation time at a point was $2 \mathrm{~s}$. The X-ray diffraction patterns were processed using the TOPAS and Eva software using the PDF2 database.

The morphology and crystals size of silicoaluminophosphates were investigated by scanning electron microscopy (SEM) on a JEOL JSM-6490LV electron microscope at an accelerating voltage of $10 \mathrm{kV}$

The specific surface area and total pore volume were measured by low-temperature nitrogen adsorption-desorption on a Nova $1200 \mathrm{e}$ sorbtometer. The BET specific surface area was calculated at a relative partial pressure $\mathrm{P} / \mathrm{P}_{0}=0.2$. The volume of micropores was calculated by the t-plot method [19].

\section{RESULTS AND DISCUSSION}

\subsection{Chemical and phase composition of the obtained materials}

It was found that the $\mathrm{Si} / \mathrm{Al}$ atomic ratio in all synthesized samples is close to 15 .

As is well known from [20] that the porous structure of silicoaluminophosphates strongly depends on the silicon content in the aluminophosphate lattice. Table 1 shows the chemical compositions of the initial silicoaluminophosphate gel (Gel-SAPO) and its crystallization product (Meso-SAPO-11). It is seen that the silicon content in the gel is higher than its content in the crystallization product. Such inconsistencies are due to incomplete incorporation of silicon atoms into the aluminophosphate lattice. Apparently, some of the remaining silicon remains is in the mother liquor.

Table 1. Elemental Analysis And Phase Composition Of The Original Silicoaluminophosphate Gel And Crystalline Silicoaluminophosphate

\begin{tabular}{|c|c|c|c|}
\hline Sample & $\begin{array}{c}\text { Chemical } \\
\text { composition }\end{array}$ & $\begin{array}{c}\text { Phase } \\
\text { composition }\end{array}$ & $\begin{array}{c}\text { Degree of } \\
\text { crystallinit } \\
\text { y, \% rel. }\end{array}$ \\
\hline Gel-SAPO & $\mathrm{Al}_{1.00} \mathrm{P}_{0.94} \mathrm{Si}_{0.39}$ & Am.SAPO-11 & - \\
\hline $\begin{array}{c}\text { Meso- } \\
\text { SAPO-11 }\end{array}$ & $\mathrm{Al}_{1.00} \mathrm{P}_{0.95} \mathrm{Si}_{0.32}$ & SAPO-11 & 92 \\
\hline \multicolumn{3}{|c|}{ Conditions: Am.SAPO-11 - amorphous } \\
silicoaluminophosphate
\end{tabular}

Figure 1 shows X-ray diffraction patterns for the gel and its crystallization product. It is seen that the gel is an amorphous material; it is characterized by a wide halo in the range from 20 to $30^{\circ} 2 \Theta$. The product of gel crystallization is SAPO-11 silicoaluminophosphate with high phase purity and high degree of crystallinity close to $92 \%$.
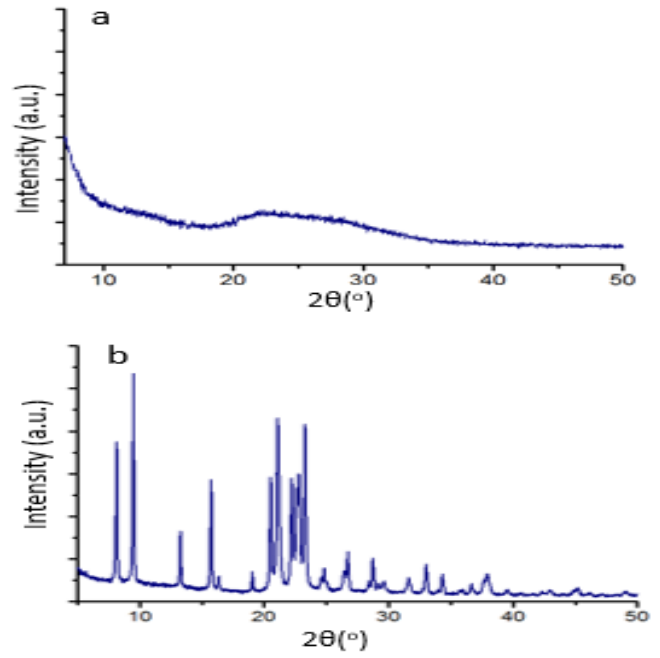

Fig. 1. X-ray diffraction patterns of samples of SAPO-11: (a) Gel-SAPO; (b) Meso-SAPO-11

\subsection{The porous structure and acidity of the obtained materials}

Table 2 shows the characteristics of the porous structure for a crystalline sample of silicoaluminophosphate. It can be seen that this sample has a specific surface area of more than BET surface area $\sim 207 \mathrm{~m}^{2} / \mathrm{g}$ and a micropore volume Vmicro $0.08 \mathrm{~cm}^{3} / \mathrm{g}$. It should be noted that for the specified sample, in addition to micropores, mesopores Vmeso $\sim 0.09 \mathrm{~cm}^{3} / \mathrm{g}$ are also observed. Thus, a sample of crystalline silicoaluminophosphate SAPO-11 is a material with a micromesoporous structure. These results are close to the results we obtained earlier for crystalline aluminophosphate molecular sieve [21], in the synthesis of which its isopropoxide was used as a source of aluminum

Table 2. Characteristics of the porous structure of Nano-SAPO11

\begin{tabular}{|c|c|c|c|}
\hline Sample & $\begin{array}{c}\mathbf{S}_{\text {BET }}{ }^{\mathbf{a}} \\
\left(\mathbf{m}^{\mathbf{2}} / \mathbf{g}\right)\end{array}$ & $\begin{array}{c}\mathbf{V}_{\text {micro }}{ }^{\mathbf{b}} \\
\left(\mathbf{c m}^{\mathbf{3}} / \mathbf{g}\right)\end{array}$ & $\begin{array}{c}\mathbf{V}_{\text {meso }} \mathbf{c} \\
\left(\mathbf{c m}^{\mathbf{3}} / \mathbf{g}\right)\end{array}$ \\
\hline Nano-SAPO-11 & 207 & 0.08 & 0.09 \\
\hline
\end{tabular}

Conditions: ${ }^{\mathrm{a}}$ surface area by method BET; ${ }^{\mathrm{b}}$ micropore volume; ${ }^{\mathrm{c}}$ mesopore volume

\section{A sample morphology}

Figure 2 shows a scanning electron microscope image analysis. The Figure 2 shows SEM images with different magnifications for a sample of crystalline silicoaluminophosphate SAPO-11. It can be seen that with a magnification of 2000 times, the crystals are spherical aggregates ranging in size from 8 to $10 \mu \mathrm{m}$. It should be noted that at a higher magnification $(20,000)$, it can be seen these aggregates consist of smaller crystals ranging in size from 100 to $200 \mathrm{~nm}$.

It is known [22] that the size of crystals of zeolite materials strongly depends on the degree of supersaturation with respect to crystallization nuclei. So the formation of highly dispersed crystals is due to high degrees of supersaturation. Apparently, due to the high reactivity of aluminum isopropoxide, the gel prepared on its basis makes it possible to create high supersaturations in the nuclei in the gel during crystallization. Due to the high excess of surface energy, characteristic of all nanoparticles, the resulting highly dispersed crystals begin to grow together into larger aggregates. However, due to their incomplete fusion, mesopores are formed. Thus, the reason for the formation of mesopores in the crystalline sample of SAPO11 is due to incomplete intergrowth of primary nanocrystals. 

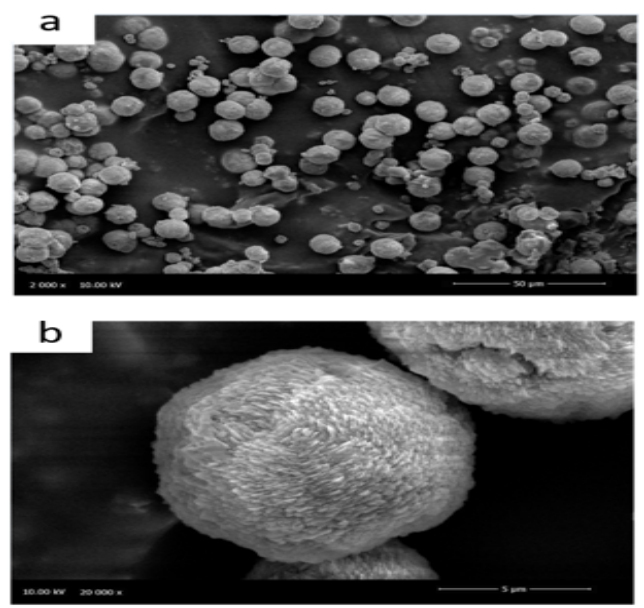

Fig. 2. SEM image of sample Nano-SAPO-11

\section{CONCLUSION}

1. The paper proposes a promising for practical implementation method for the synthesis of silicoaluminophosphate molecular sieve SAPO-11 of high phase purity and high degree of crystallinity $(92 \%)$ with a micro-mesoporous structure. The method is based on crystallization of the initial silicoaluminophosphate gel with the following composition $1.0 \mathrm{Al}_{2} \mathrm{O}_{3} \cdot 1.0 \mathrm{P}_{2} \mathrm{O}_{5} \cdot 0.4 \mathrm{SiO}_{2} \cdot 1.0 \mathrm{DPA} \cdot 30 \mathrm{H}_{2} \mathrm{O}$, in the preparation of which its isopropoxide was used as a source of aluminum.

2. Using scanning electron microscope, it was shown that SAPO- 11 crystals are spherical aggregates ranging in size from 8 to 10 microns, which are formed from nanocrystals with a size of $\sim 100-200 \mathrm{~nm}$.

3. It was found that the secondary porous structure of the obtained material is formed by intergrowths of nanocrystals, between which mesopores are formed.

4. The resulting material has a specific surface of $207 \mathrm{~m}^{2} / \mathrm{g}$, a volume of micro- and mesopores of 0.08 and $0.09 \mathrm{~cm}^{3} / \mathrm{g}$, respectively.

\section{ACKNOWLEDGMENT}

The work was carried out within the framework of the state assignments of Institute of Petrochemistry and Catalysis of Russian Academy of Sciences on the topic "Zeolitic materials of various structural types with a high degree of crystallinity with a hierarchical porous structure - a new generation of catalysts for the synthesis of practically important petrochemical products" registration No. AAAA-A19119022290006-2. The results were obtained with the financial support of the Russian Federation represented by the Ministry of Education and Science of the Russian Federation by Grant Federal Target Program No. 019-05-595-000-058 using the equipment of the "Agidel" center for shared use at the Institute of Petroleum Chemistry and Catalysis, Ufa Federal Research Center, Russian Academy of Sciences.

\section{REFERENCES}

[1] Dhanapalan K., Nachiyappan L. and Bommasamudram S., Navamoney J. J., Hydroisomerization of n-Octane over Bifunctional $\mathrm{Ni}-\mathrm{Pd} / \mathrm{HY}$ Zeolite Catalysts. Industrial \& Engineering Chemistry Research 2008, 47 (17), 6538-6546.

[2] Taylor R. J., Petty R. H. Selective hydroisomerization of long chain normal paraffins //Applied Catalysis A: General. - 1994. T. 119. - №. 1. - P. 121-138.

[3] Calemma V. et al. Hydrocracking and hydroisomerization of long-chain n-paraffins. Reactivity and reaction pathway for base oil formation //Industrial \& engineering chemistry research. 2004. - T. 43. - №. 4. - P. 934-940.

[4] Gomes L. C. et al. Hydroisomerization of n-hexadecane using Pt/alumina-Beta zeolite catalysts for producing renewable diesel with low pour point //Fuel. - 2017. - T. 209. - P. 521-528.

[5] H. Deldari. Suitable catalysts for hydroisomerization of longchain normal paraffins // Applied Catalysis A: General. 2005. Vol. 293. Pp.1-10.

[6] Schenk M. et al. Shape selectivity in hydrocarbon conversion //Angewandte Chemie International Edition. - 2001. - T. 40. №. 4. - P. 736-739.

[7] Yadav R., Sakthivel A. Silicoaluminophosphate molecular sieves as potential catalysts for hydroisomerization of alkanes and alkenes //Applied Catalysis A: General. - 2014. - T. 481. - P. 143-160.

[8] Vagif M. Akhmedov, Soliman H. Al-Khowaiter. Recent Advances and Future Aspects in the Selective Isomerization of High n-Alkanes // Catalysis Reviews. 2007. Vol. 49. Pp.33-139.

[9] Xiao Cui, Yuxiang Liu, Xinmei Liu. Controlling Acidic Sites to Improve Hydroisomerization Performance of Pt/SAPO-11 Catalysts // Catal Lett. 2015. Vol.145 No. 7. Pp.1464-1473.

[10] Lin Guo, Yu Fan, Xiaojun Bao, Gang Shi, Haiyan Liu. Two-stage surfactant-assisted crystallization for enhancing SAPO-11 acidity to improve n-octane di-branched isomerization // Journal of Catalysis. 2013. Vol. 301. Pp.162-173.

[11] Koohsaryan E., Anbia M. Nanosized and hierarchical zeolites: A short review //Chinese Journal of Catalysis. - 2016. - T. 37. - №. 4. - P. 447-467.

[12] Feliczak-Guzik A. Hierarchical zeolites: Synthesis and catalytic properties //Microporous and Mesoporous Materials. - 2018. - T 259. - P. 33-45

[13] Oruji S., Khoshbin R., Karimzadeh R. Preparation of hierarchical structure of Y zeolite with ultrasonic-assisted alkaline treatment method used in catalytic cracking of middle distillate cut: The effect of irradiation time //Fuel Processing Technology. - 2018. - T. 176. - P. 283-295.

[14] Qin Z. et al. Mesoporous Y zeolite with homogeneous aluminum distribution obtained by sequential desilication-dealumination and its performance in the catalytic cracking of cumene and 1, 3, 5-triisopropylbenzene //Journal of Catalysis. - 2011. - T. 278. №. 2. - P. 266-275.

[15] Yu Fan, Han Xiao, Gang Shi, Haiyan Liu, Xiaojun Bao. Alkylphosphonic acid- and small amine-templated synthesis of hierarchical silicoaluminophosphate molecular sieves with high isomerization selectivity to di-branched paraffins // Journal of Catalysis. 2012. Vol. 285. Pp.251-259.

[16] Minkee Choi, Rajendra Srivastava, Ryong Ryoo. Organosilane surfactant-directed synthesis of mesoporous aluminophosphates constructed with crystalline microporous frameworks // Chem. Commun. 2006. Pp.4380-4382.

[17] Danny Verboekend, Maria Milina, Javier Pérez-Ramírez. Hierarchical Silicoaluminophosphates by Postsynthetic Modification: Influence of Topology, Composition, and Silicon Distribution // Chem. Mater. 2014. Vol. 26. Pp. 4552-4562.

[18] Lingmei Yang, Shiyou Xing, Hongzhe Sun, Changlin Miao, Ming Li, Pengmei Lv, hongming Wang, Zhenhong Yuan. Citricacid-induced mesoporous SAPO-11 loaded with highly dispersed nickel for enhanced hydroisomerization of oleic acid to isoalkanes // Fuel Processing Technology. 2019. Vol. 187. Pp.5262.

[19] Kanaan R. A., Isomerization of n-hexane in the presence of catalysts based on granular mordenite-type zeolite without binders, Ph.D thesis- USPTU, 2013Pp.1-107.

[20] Pastore H. O., Coluccia S., Marchese L. Porous aluminophosphates: from molecular sieves to designed acid catalysts //Annu. Rev. Mater. Res. 2005. Vol. 35. Pp.351-395.

[21] M. R. Agliullin, Z. R. Khairullina, A. V. Faizullin, B. I. Kutepov. Crystallization of $\mathrm{AlPO}_{4}-11$ Aluminophosphate from Various Aluminum Sources // Petroleum Chemistry. 2019. No. 3. Vol. 59. Pp.349-353.

[22] Cejka J., Corma A., Zones S. Zeolites and catalysis: synthesis, reactions and applications // Wiley-VCH, Weinheim. 2010.918 p. 